\title{
Regulatory effects of four ginsenoside monomers in humoral immunity of systemic lupus erythematosus
}

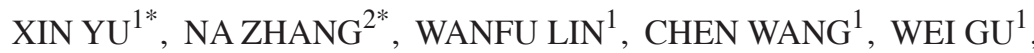 \\ CHANGQUAN LING ${ }^{1}$, YINGLU FENG ${ }^{2}$ and YONGHUA SU ${ }^{1}$ \\ ${ }^{1}$ Changhai Hospital of Traditional Chinese Medicine, Second Military Medical University, Shanghai 200433; \\ ${ }^{2}$ Department of Traditional Chinese Medicine, 401 Hospital of The Chinese People's Liberation Army, Qingdao, \\ Shandong 266071, P.R. China
}

Received March 13, 2017; Accepted October 25, 2017

DOI: $10.3892 /$ etm.2017.5657

\begin{abstract}
Ginsenosides Rb1, Rh1, Rg1 and Rg3 are known as the main active components extracted from the roots of the Panax ginseng C.A. Meyer, and were reported to have immunoregulatory effects. Disruption of B-cell immune regulation during the pathogenesis of systemic lupus erythematosus (SLE) may lead to the production of large amounts of antibodies. The present study investigated the effects of the four ginsenoside monomers on B-cell immune regulation and observed that they inhibited the proliferation and secretion of $\mathrm{B}$ cells induced by LPS, caused an upregulation of the expression of apoptosis-associated proteins Fas/Fas ligand and caspase-3, the expression of Fc $\gamma$ RIIB (CD32) as well as the proportion of inactive $\mathrm{B}$ cells $\left(\mathrm{CD} 19^{+} \mathrm{CD} 27^{-}\right)$. These results indicate that Rb1, Rh1, Rg1 and Rg3 inhibit the humoral immunity of SLE, among which Rh1 exhibited the most obvious inhibitory effect.
\end{abstract}

\section{Introduction}

Systemic lupus erythematosus (SLE) is a human autoimmune disease with diverse clinical manifestations, including systemic

Correspondence to: Professor Yinglu Feng, Department of Traditional Chinese Medicine, 401 Hospital of The Chinese People's Liberation Army, 22 Minjiang Road, Qingdao, Shandong 266071, P.R. China

E-mail: ylfeng1975@126.com

Professor Yonghua Su, Changhai Hospital of Traditional Chinese Medicine, Second Military Medical University, 168 Changhai Road, Shanghai 200433, P.R. China

E-mail: suyonghuasmmu@126.com

${ }^{*}$ Contributed equally

Abbreviations: GS, ginsenoside; SLE, systemic lupus erythematosus; BLyS, B lymphocyte stimulator; BAFF, B cell activating factor; $\beta 2 \mathrm{M}, \beta 2$-microglobulin

Key words: systemic lupus erythematosus, ginsenoside monomer, humoral immunity, Traditional Chinese Medicine and organ damage. In most cases, vital organs including the brain, heart, joints, skin and kidneys are involved (1). In the US population, the yearly incidence of SLE was 5.1 and the prevalence was 52.2 per 100,000 individuals (2). The pathogenesis of SLE caused by immune pathway abnormalities mainly involves the following aspects (3-5): Loss of self-tolerance to nuclear antigens, abnormalities of immune regulation and immune complex clearance disorders. Among these, aberrant immune regulation is the central link, which is characterized by a high degree of B-cell activation and secretion of large numbers of autoantibodies.

Ginsenosides (GS), the major active components of the traditional Chinese medicine Panax ginseng C.A. Meyer, have been reported to have regulatory effects on the immune system. However, previous studies mainly focused on the effects of GS on T-cell signaling pathways. For instance, GRg1 was reported to enhance $\mathrm{CD} 4^{+} \mathrm{T}$-cell activities, modulate type I helper cell (Th1)/Th2 differentiation and increase the ratio of $\mathrm{CD}^{+}{ }^{+} \mathrm{CD} 4^{+}$to $\mathrm{CD}^{+}{ }^{+} \mathrm{CD} 8^{+} \mathrm{T}$ cells and $\mathrm{CD} 4{ }^{+} \mathrm{CD} 25^{+}$forkhead box (Fox)p $3^{+}$regulatory $\mathrm{T}$ cells in the blood in 1-methyl-4phenyl-1,2,3,6-tetrahydropyridine-induced mice (6-8). Furthermore, GRg1, GRh1 and 20(S)-protopanaxtriol not only inhibited 2,4,6-trinitrobenzene sulfonic acid (TNBS)-induced nuclear factor- $\kappa \mathrm{B}$ activation but restored TNBS-induced Th17/T-regulatory cell (Treg) imbalance (9). In addition, GRp1 was revealed to promote the differentiation of the memory types of $\mathrm{CD}^{+}{ }^{+} \mathrm{Foxp}^{+} \mathrm{CD} 62 \mathrm{~L}$ (low) Tregs (10). However, few studies have investigated the effects of GS and their monomers on B-cell immune pathways, or the regulatory effects of GS on B-cell immune function in SLE.

Therefore, the present study focused on effects of GS on the B-cell immune pathway. Four major active GS monomers were selected to observe their effects on humoral immunity and to determine whether they had a positive effect on the humoral immune system as a potential treatment for SLE.

\section{Materials and methods}

Samples. Peripheral blood samples were obtained from 2 healthy, adult females during a physical examination at Changhai Hospital (Shanghai, China) with informed consent (age range 25-28 years, mean 26.5 years), and the study protocol 
was approved by the Medical Ethics Committee of Changhai Hospital affiliated to the Second Military Medical University (Shanghai, China). To obtain a peripheral blood mononuclear cell (PBMC) suspension, $2 \mathrm{ml}$ of peripheral blood from healthy adults was added to the upper layer of human lymphocyte separation medium (Cedarlane, Burlington, ON, Canada) and centrifuged for $20 \mathrm{~min}$ at 2,200 $\mathrm{x} \mathrm{g}$ at room temperature. The leukocyte-rich supernatant was recovered and centrifuged for $10 \mathrm{~min}$ at $2,200 \mathrm{x} \mathrm{g}$ in $5 \mathrm{ml} \mathrm{PBS}$ at room temperature, which was repeated 3 times. Thus, the mononuclear cells were isolated and then resuspended in polypropylene tubes in $1 \mathrm{ml}$ RPMI-1640 medium (GE Healthcare Life Sciences, Logan, UT, USA).

B-cell isolation. $\mathrm{CD} 19^{+} \mathrm{B}$ cells were isolated by positive cell sorting using immunomagnetic beads. PBMCs were resuspended with human CD19 MicroBeads (Miltenyi Biotec, Bergisch Gladbach, Germany) for $15 \mathrm{~min}$ at $4^{\circ} \mathrm{C}$ for magnetic labeling, the LS columns were then placed in a magnetic field, and subsequently, the labeled $\mathrm{CD} 19^{+} \mathrm{B}$ cells were collected. The purity of the isolated $\mathrm{CD} 19^{+} \mathrm{B}$ cells was $97-99 \%$ according to by flow cytometric analysis.

Cell culture. CD19+ B cells were cultured in RPMI1640 medium containing 10\% fetal bovine serum (FBS; GE Healthcare Life Sciences) and $1 \%$ antibodies (100 U/ml penicillin and $100 \mu \mathrm{g} / \mathrm{ml}$ streptomycin) in a humidified atmosphere containing $5 \% \mathrm{CO}_{2}$ at $37^{\circ} \mathrm{C}$.

5-Bromo-2'-deoxyuridine (BrdU) cell proliferation assay. Cell proliferation was determined by labeling. In the 12 -well tissue culture plates, cells were divided into 14 groups: Control group, LPS (1 $\mu \mathrm{g} / \mathrm{ml}$; Sigma-Aldrich; Merck KGaA, Darmstadt, Germany) group, GRb1 (0.1, 1 and $10 \mathrm{mg} / \mathrm{l})+\mathrm{LPS}$ $(1 \mu \mathrm{g} / \mathrm{ml})$ group, GRh1 $(0.1,1$ and $10 \mathrm{mg} / \mathrm{l})+\operatorname{LPS}(1 \mu \mathrm{g} / \mathrm{ml})$ group, GRg1 $(0.1,1$ and $10 \mathrm{mg} / \mathrm{l})+\mathrm{LPS}(1 \mu \mathrm{g} / \mathrm{ml})$ group, $\operatorname{GRg} 3(0.1,1$ and $10 \mathrm{mg} / \mathrm{l})+\operatorname{LPS}(1 \mu \mathrm{g} / \mathrm{ml})$ group. GRb1, GRh1, GRg1 and GRg3 were supplied by Shanghai Dongfang Pharmaceutical (Shanghai, China), and each group was set up

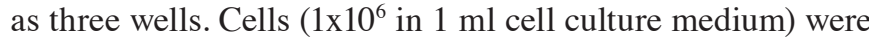
added to the plates and grown for $68 \mathrm{~h}$, and then incubated with BrdU for $3 \mathrm{~h}$ for labeling, followed by fixing. Subsequently, BrdU incorporation into the cellular DNA was measured by flow cytometric analysis.

ELISA. The concentrations of immunoglobulin (Ig)G and IgM were measured by ELISA kits according to the manufacturer's instructions (Bender MedSystems, Vienna, Austria). The optical density of the microwells was read at $450 \mathrm{~nm}$.

Western blot analysis. B cells were divided into 6 groups: Control group, LPS (1 $\mu \mathrm{g} / \mathrm{ml})$ group, GRb1 (10 mg/l) + LPS $(1 \mu \mathrm{g} / \mathrm{ml})$ group, GRh1 (10 mg/l) + LPS (1 $\mu \mathrm{g} / \mathrm{ml})$ group, GRg1 (10 mg/l) + LPS (1 $\mu \mathrm{g} / \mathrm{ml})$ group, GRg3 $(10 \mathrm{mg} / \mathrm{l})+\mathrm{LPS}$ $(1 \mu \mathrm{g} / \mathrm{ml})$ group and grown in RPMI-1640 medium for $68 \mathrm{~h}$. After treatment, cells were washed with PBS and fully lysed in radioimmunoprecipitation assay buffer (Solarbio, Beijing, China) at $4^{\circ} \mathrm{C}$. The protein concentration in the extract was determined using a bicinchoninic acid assay (Thermo Fisher Scientific, Inc., Waltham, MA, USA). Equal amounts of
Table I. Primer sequences of target genes for reverse transcription-quantitative polymerase chain reaction.

\begin{tabular}{lll}
\hline Gene & Direction & \multicolumn{1}{c}{ Sequence } \\
\hline BCMA & Forward & 5'-AAAGAGCAGGACTGGTGATG-3' \\
& Reverse & 5'-ATCTCCGTAGCACTCAAAGC-3' \\
BAFF-R & Forward & 5'-CTTTCTGGGACCAGGCTAAC-3' \\
& Reverse & 5'-GTGAGGTCTGAAGCCAAAGG-3' \\
TACI & Forward & 5'-AGCTCAGGAGCCCAGTGAAC-3' \\
& Reverse & 5'-ACCAGGAAGCAGCAGAGGAC-3' \\
BlyS & Forward & 5'-TCACGGTGGTGTCTTTCTAC-3' \\
& Reverse & 5'-TGCTGTTCTGACTGGAGTTG-3' \\
$\beta_{2} \mathrm{M}$ & Forward & 5'-GTTTCATCCATCCGACATG-3' \\
& Reverse & 5'-TAACTATCTTGGGCTGTGAC-3' \\
BAFF & Forward & 5'-TCACGGTGGTGTCTTTCTAC-3' \\
& Reverse & 5'-TGCTGTTCTGACTGGAGTTG-3' \\
GAPDH & Forward & 5'-CACCCACTCCTCCACCTTTG-3' \\
& Reverse & 5'-CCACCACCCTGTTGCTGTAG-3'
\end{tabular}

BCMA, B-cell maturation antigen; BAFF-R, B cell activating factor receptor; TACI, transmembrane activator and CAML interactor; BlyS, B lymphocyte stimulator; $\beta_{2} \mathrm{M}, \beta 2$-microglobulin; BAFF, B cell activating factor.

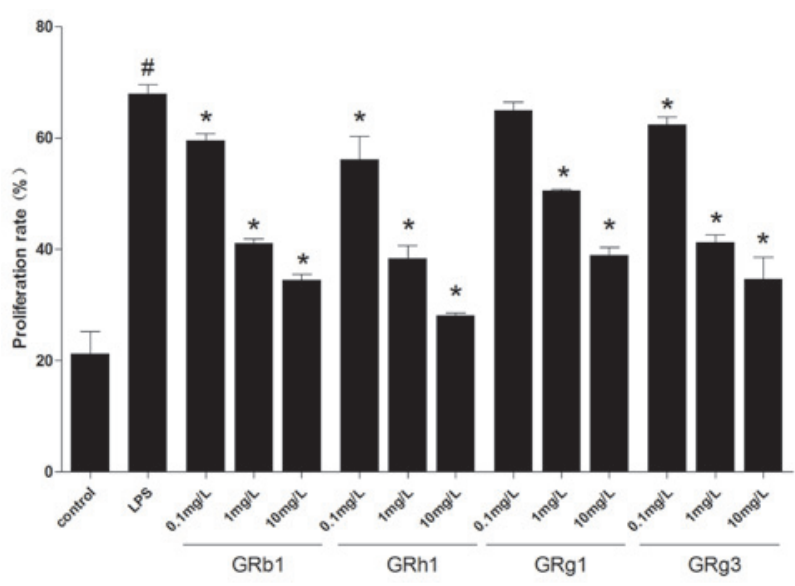

Figure 1. Effects of the four ginsenoside monomers on LPS-induced B-cell proliferation. Cell proliferation was determined by a bromodeoxyuridine assay. B cells were treated with LPS $(1 \mu \mathrm{g} / \mathrm{ml})$ or LPS combined with GRb1, GRh1, GRg1 or GRg3 $(0.1,1$ or $10 \mathrm{mg} / \mathrm{l})$ for $68 \mathrm{~h}$. Values are expressed as the mean \pm standard deviation ( $\mathrm{n}=3$ in each group). ${ }^{~} \mathrm{P}<0.05$ vs. control group; ${ }^{*} \mathrm{P}<0.05$ vs. LPS group. LPS, lipopolysaccharide.

protein $(25 \mu \mathrm{g})$ were subjected to $10 \%$ SDS-PAGE and electrophoretically transferred onto polyvinylidene difluoride membranes. Membranes were blocked with 5\% skimmed milk powder dissolved in tris-buffered saline containing Triton X (TBST) at room temperature for $2 \mathrm{~h}$, and then incubated with antibodies against Fas (1:1,000 dilution; cat. no. Ab133619; Abcam, Cambridge, UK), Fas ligand (FasL; 1:500 dilution; cat. no. Ab68338; Abcam), caspase-3 (1:500 dilution; cat. no. Ab44976; Abcam) and GAPDH (1:1,500 dilution; cat. no. 5174; Cell Signaling Technologies, Inc., Danvers, MA, USA) overnight at $4^{\circ} \mathrm{C}$. Following washing 
A

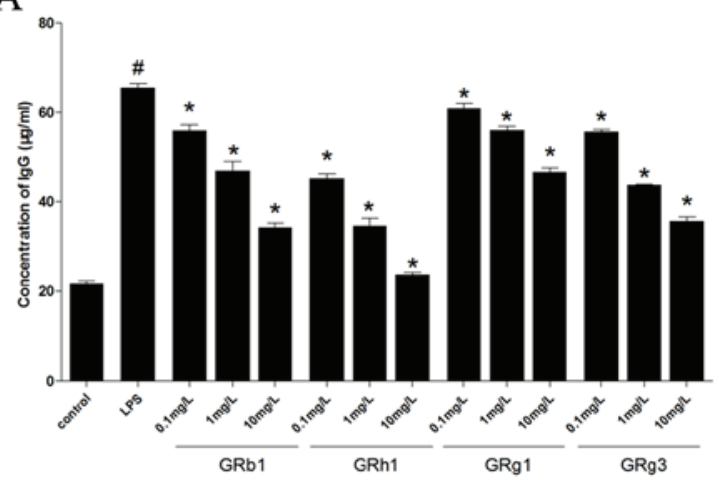

B

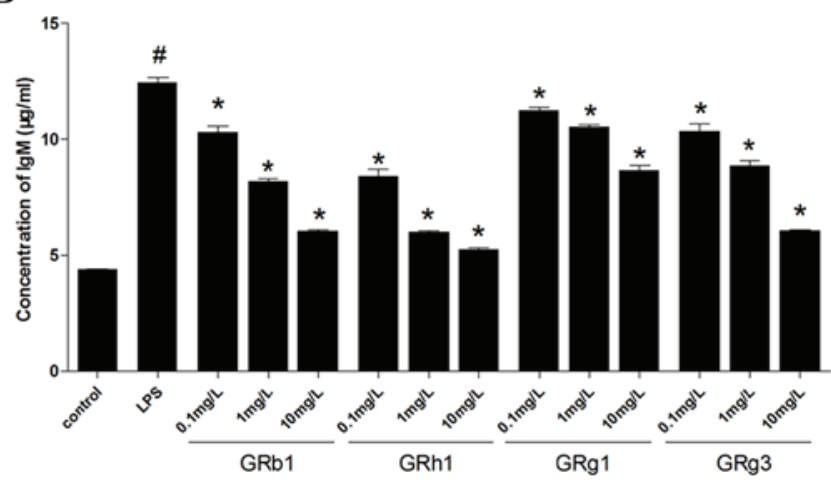

Figure 2. Effects of the four ginsenoside monomers on the secretion of (A) IgG and (B) IgM. The concentration of IgG and IgM was analyzed by ELISA. B cells were treated with LPS $(1 \mu \mathrm{g} / \mathrm{ml})$ or LPS combined with GRb1, GRh1, GRg1 or GRg3 $(0.1,1$ or $10 \mathrm{mg} / \mathrm{l})$ for $68 \mathrm{~h}$. Values are expressed as the mean \pm standard deviation ( $\mathrm{n}=3$ in each group). ${ }^{\#} \mathrm{P}<0.05$ vs. control group; ${ }^{*} \mathrm{P}<0.05$ vs. LPS group. Ig, immunoglobulin; LPS, lipopolysaccharide.

with TBST buffer 3 times for 5 min each, membranes were incubated with horseradish peroxidase-conjugated secondary antibody (goat anti-mouse, 1:1,000 dilution; cat. no. A0208; goat anti-rabbit, 1:1,000 dilution; cat. no. A0216; donkey anti-goat, 1:1,000 dilution; cat. no. A0181; all, Beyotime Institute of Biotechnology, Inc., Haimen, China) at room temperature for $1 \mathrm{~h}$. Protein bands were detected using an enhanced chemiluminescence detection kit (EMD Millipore, Billerica, MA, USA). GAPDH was used as the internal control and the relative values of target protein were corrected in accordance with the absorbency of the internal control.

Reverse transcription-quantitative polymerase chain reaction $(R T-q P C R)$. B cells were treated as for the western blot protocol, then collected with TRIzol (Thermo Fisher Scientific, Inc.) and placed on ice, and total RNA was extracted according to the manufacturer's instructions. DNase I (Thermo Fisher Scientific, Inc.) was used to eliminate DNA, and the RNA was reverse-transcribed into complementary (c) DNA using a cDNA synthesis kit (cat. no. K1622; Fermentas, Vilnius, Lithuania) according to manufacturer's protocol in a total volume of $20 \mu \mathrm{l}$ containing $2 \mu \mathrm{g}$ total RNA. The cDNA samples were used as a template to analyze the expression of B lymphocyte stimulator (BLyS), transmembrane activator (TACI), B-cell maturation antigen (BCMA), B-cell activating factor receptor (BAFF-R), $\beta 2$-microglobulin $(\beta 2 \mathrm{~m})$ and BAFF. Real-time PCR was performed in an ABI Prism 7300 (Applied Biosystems; Thermo Fisher Scientific, Inc.) using the SYBR green PCR supermix (cat. no. K0223; Thermo Fisher Scientific, Inc.). The primer sequences for real-time PCR are listed in Table I. The RT-qPCR conditions were pre-denaturation at $95^{\circ} \mathrm{C}$ for $40 \mathrm{sec}$, followed by 40 cycles of denaturation at $95^{\circ} \mathrm{C}$ for $15 \mathrm{sec}$ and annealing at $60^{\circ} \mathrm{C}$ for $45 \mathrm{sec}$. The relative expression of these genes was calculated using the $2^{-\Delta \Delta \mathrm{Cq}}$ method (11).

Flow cytometric analysis. Flow cytometric analysis was used to detect the co-stimulatory molecules on B cells. In brief, B cells were seeded into 12 -well plates at $1 \times 10^{6}$ cells in each well. The cells were then treated as above for the western blot analysis. After incubation for $68 \mathrm{~h}$, cells in each well were collected and counted. After adjusting cell density to

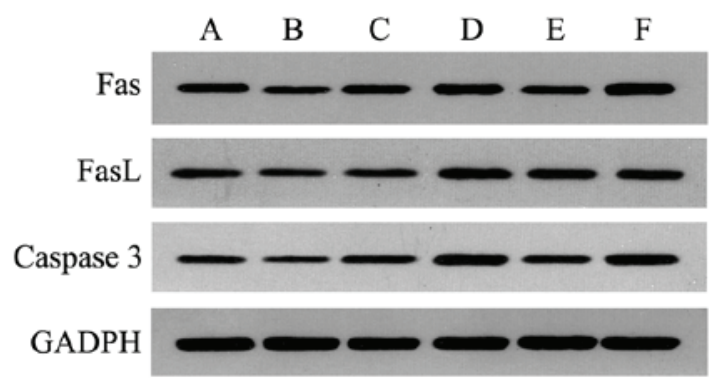

Figure 3. Effects of the four ginsenoside monomers on the expression of proteins associated with B-cell apoptosis. B cells were treated with LPS $(1 \mu \mathrm{g} / \mathrm{ml})$ or LPS combined with GRb1, GRh1, GRg1 or GRg3 $(10 \mathrm{mg} / \mathrm{l})$ for the indicated times and the whole protein extracts were then analyzed by western blot. Representative western blots for the protein expression of Fas, FasL and caspase-3 are displayed. Lanes: A, control; B, LPS; C, 10 mg/1 Rb1 + LPS; D, 10 mg/1 Rh1 + LPS; E, 10 mg/1 Rg1 + LPS; F, 10 mg/1 Rg3 + LPS. FasL, Fas ligand; LPS, lipopolysaccharide.

$1 \times 10^{6} / \mathrm{ml}, 200 \mu \mathrm{l}$ cell suspension was centrifuged for $5 \mathrm{~min}$ at $1,000 \mathrm{x}$, washed with PBS twice and re-suspended with $100 \mu 1$ PBS. Antibodies to CD19, CD27 and CD32 were added and the stained cells were analyzed by flow cytometry on a FACSCalibur (BD Biosciences, San Jose, CA, USA).

Statistical analysis. Values are expressed as the mean \pm standard deviation. The differences between groups were analyzed using SPSS 21.0 (IBM Corp., Armonk, NY, USA). Two-sided P-values and $95 \%$ confidence intervals were calculated. The statistical analysis was performed using a one-way analysis of variance followed by Dunnett's test.

\section{Results}

Effects of the four GS monomers on B-cell proliferation and secretion of IgG and IgM. Peripheral B cells in SLE patients proliferate and produce large amounts of autoantibodies. In order to observe whether GS monomers inhibit the proliferation of B cells when they are highly activated, the cells were stimulated with LPS in the presence or absence of GS monomers, and their proliferation was detected using the BrdU method. Compared with control group, B cells proliferated at a 
A

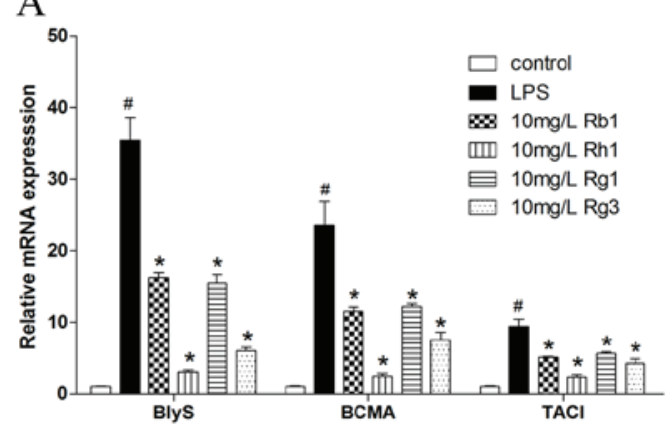

C

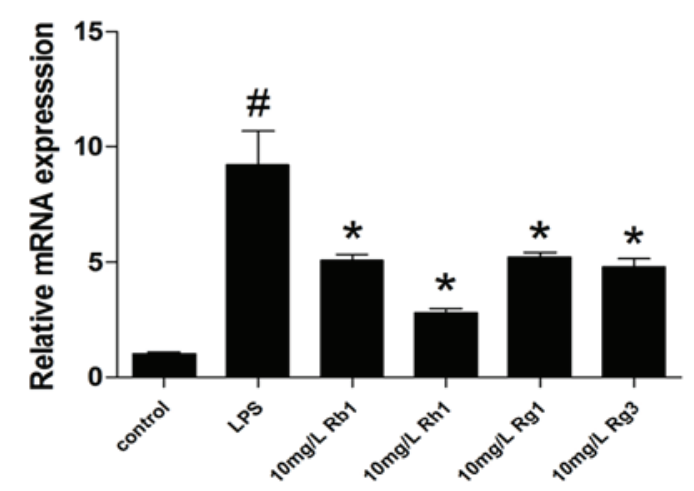

B

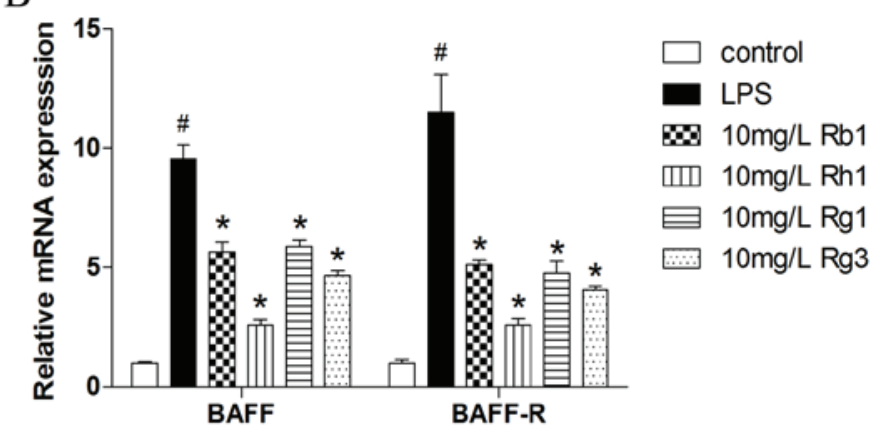

Figure 4. Effects of the four ginsenoside monomers on the mRNA expression of BLyS and BAFF, their receptors and $\beta 2 \mathrm{M}$. B cells were treated with LPS $(1 \mu \mathrm{g} / \mathrm{ml})$ or LPS combined with GRb1, GRh1, GRg1 or GRg3 (10 mg/l) for $68 \mathrm{~h}$. The expression of (A) BlyS and its receptors, (B) BAFF and its receptor and $(\mathrm{C}) \beta 2 \mathrm{M}$ was monitored by means of reverse transcription-quantitative polymerase chain reaction analysis. Values are expressed as the mean \pm standard deviation ( $\mathrm{n}=3$ in each group). ${ }^{\#} \mathrm{P}<0.05$ vs. control group; ${ }^{*} \mathrm{P}<0.05$ vs. LPS group. BCMA, B-cell maturation antigen; BAFF-R, B-cell activating factor receptor; TACI, transmembrane activator and CAML interactor; BlyS, B lymphocyte stimulator; $\beta 2 \mathrm{M}, \beta 2$-microglobulin; LPS, lipopolysaccharide.

high rate after addition of LPS (Fig. 1), which was significantly inhibited in the presence of GS monomers except for GRg1 at the low dose, and this inhibitory effect was dose-dependent.

As the secretion of autoantibodies and the incidence of SLE are closely linked (12), and the secretion of IgG and IgM has an important role in it $(13,14)$, the concentration of $\mathrm{IgG}$ and IgM was measured by ELISA. The results demonstrated that the secretion of $\operatorname{IgG}$ and $\operatorname{IgM}$ was increased compared with that in the control group (Fig. 2). However, this LPS-induced secretion of $\operatorname{IgG}$ and IgM was significantly suppressed by treatment with GS monomers.

Effects of the four GS monomers on B-cell apoptosis. As B-cell hyperactivity and production of autoantibodies directed to components of the cell nuclei are contributing factors of SLE (15) and the promotion of autoreactive B-cell apoptosis may reduce the damage caused by SLE, the expression of several groups of B-cell apoptosis-associated proteins (Fas/FasL and caspase-3) was detected by western blot analysis, revealing that LPS reduced the expression of Fas/FasL and caspase-3. After addition of GS monomers $(10 \mathrm{mg} / \mathrm{ml})$, the LPS-induced decrease in the expression of Fas/FasL and caspase-3 was inhibited (Fig. 3).

Effects of the four GS monomers on the mRNA expression of $B L y S$ and $B A F F$, their receptors and $\beta 2 M$. The above mentioned results indicate that GS monomers inhibit LPS-induced B-cell proliferation, but the underlying mechanism was required to be elucidated. BLyS and BAFF are endogenous proteins that have important roles in the differentiation and proliferation of B lymphocytes, and enhanced levels of BlyS and BAFF have been reported in lupus and other rheumatic diseases (16-18). The mRNA expression of BlyS and BAFF and their receptors was quantified by RT-qPCR. The results indicated that the mRNA expression of BlyS and its receptors BCMA and TACI (Fig. 4A), as well as BAFF and its receptor BAFF-R (Fig. 4B) increased after addition of LPS, while this increase was inhibited in the presence of the GS monomers. As $\beta 2 \mathrm{M}$ levels are a useful indicator of disease activity in SLE $(19,20)$, RT-qPCR was used to detect the mRNA expression of $\beta 2 \mathrm{M}$, revealing that GS monomers caused a significant reduction of the LPS-stimulated $\beta 2 \mathrm{M}$ expression (Fig. 4C).

Effects offour GS monomers on B-cell subsets. As the proportions of $\mathrm{CD} 19^{+}$and $\mathrm{CD} 27^{+} \mathrm{B}$-cell subsets in the peripheral blood of patients with SLE are of high significance $(21,22)$, the present study assessed the expression of these B-cell subsets by flow cytometry. The results revealed that the proportion of $\mathrm{CD} 27^{+} \mathrm{B}$-cells was increased, while that of $\mathrm{CD} 19^{+} \mathrm{B}$ cells was decreased after addition of LPS. However, these LPS-induced effects were significantly inhibited in the presence of GRb1, GRh1 and GRg3 but not GRg1 (Fig. 5).

Fc $\gamma$ RIIB (CD32) is an important inhibitory receptor on the B-cell surface, which transmits an inhibitory signal and reduces the immune response intensity upon binding to a ligand (23). In the present study, the expression of Fc $\gamma$ RIIB was detected, revealing that LPS largely reduced the expression of 

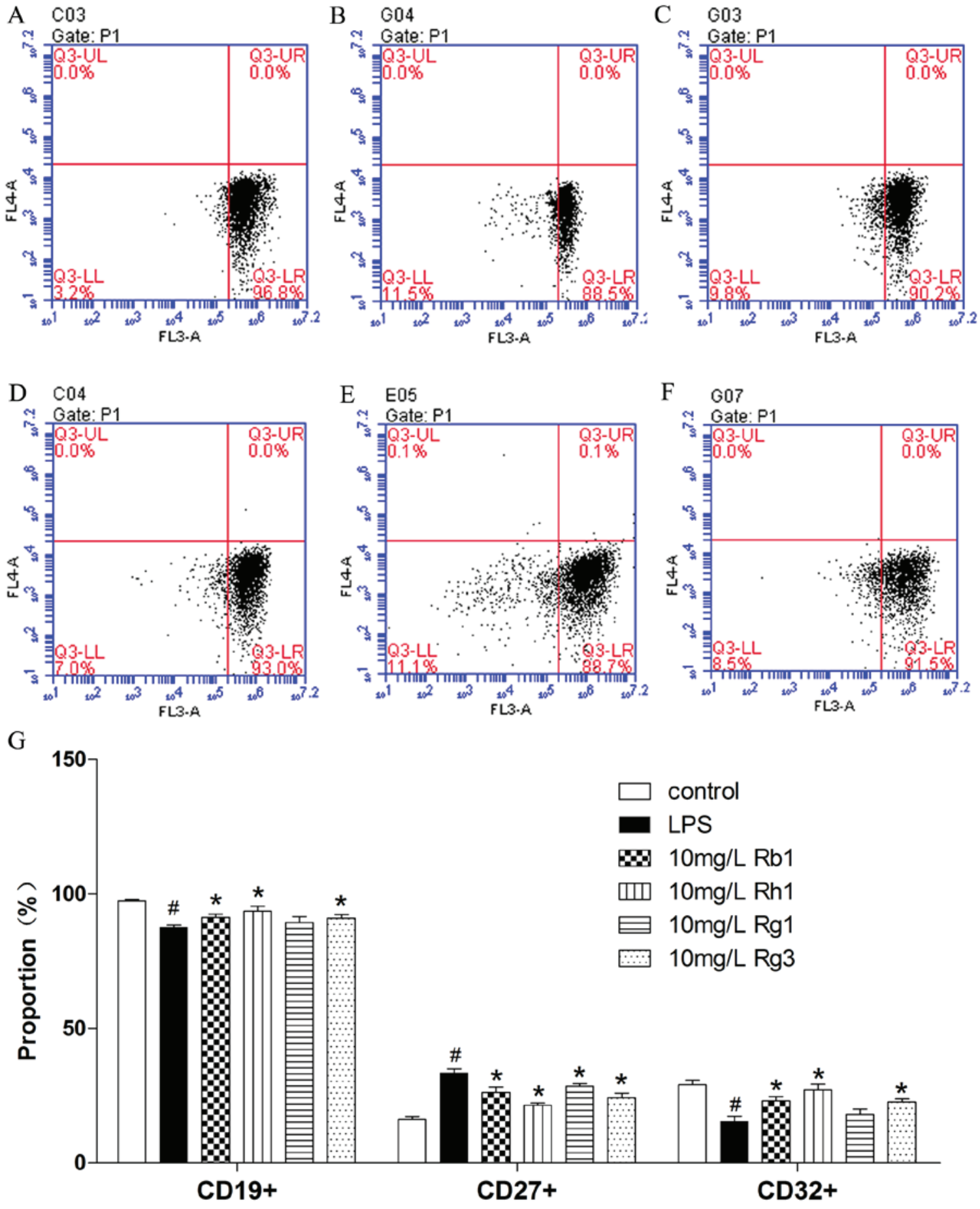

Figure 5. Effects of four ginsenoside monomers on B-cell subsets. B cells were treated with LPS $(1 \mu \mathrm{g} / \mathrm{ml})$ or LPS combined with GRb1, GRh1, GRg1 or

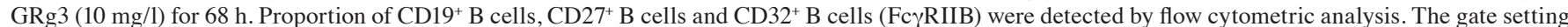
distinguished between negative (lower left) and positive (lower right). Proportion of CD19+ $\mathrm{B}$ cells in (A) the control group, (B) LPS group, (C) LPS+Rb1 group, (D) LPS+Rh1 group, (E) LPS+Rg1 group and (F) LPS+Rg3 group (proportion of CD27+ and CD32 ${ }^{+} \mathrm{B}$ cells in each group is not displayed here). (G) Statistical analysis of the proportion of $\mathrm{CD} 19^{+}, \mathrm{CD} 27^{+}$and $\mathrm{CD} 32^{+} \mathrm{B}$ cells. Values are expressed as the mean \pm standard deviation ( $\mathrm{n}=3$ in each group). ${ }^{*} \mathrm{P}<0.05 \mathrm{vs}$. control group; ${ }^{*} \mathrm{P}<0.05$ vs. LPS group. LPS, lipopolysaccharide.

Fc $\gamma$ RIIB, which was inhibited by GRb1, GRh1 and GRg3 but not GRg1 (Fig. 5).

\section{Discussion}

The pathogenesis of SLE is complex and previous studies indicate that immune dysfunction is one of the major causes of its onset $(24,25)$. GS are the major components extracted from Panax ginseng C.A. Meyer, whose immunomodulatory effect has been demonstrated in numerous studies (26-28). In the present study, LPS was used to stimulate the proliferation of immune cells by adding it to $\mathrm{CD} 19^{+} \mathrm{B}$ cells extracted from the peripheral blood of healthy adults to simulate the humoral immune enhancement status of SLE, and the four GS monomers GRg1, GRb1, GRh1 and GRg3 were selected to study the effect of GS on the LPS-induced humoral immune system. 
B-cell proliferation and activation are regulated by multiple factors. First, T-cell signaling is necessary for B-cell activation: T-cell proliferation, apoptosis and regulatory dysfunction are factors that affect the sustainment of a highly active status of B cells (29). Furthermore, the autoregulation of B-cells has a role in SLE, and the effects of abnormal B-cell apoptosis, as well as aberrant expression of Fcr receptor and B-cell stimulating factors on the proliferation of $\mathrm{B}$ cells have been studied in association with the pathogenesis $(30,31)$. Finally, antigen-presenting cells have an impact on B-cell regulation: A series of immune signaling molecules, including costimulatory factors, are involved in the regulation of immune synapse formation and signal transduction (32). The present study mainly investigated the effects of GS on B-cell autoregulation.

Initially, the BrdU assay was used to investigate the anti-proliferative effect of the four GS monomers on highly activated $\mathrm{B}$ cells, revealing that the GS monomers inhibited the proliferation of B cells in a dose-dependent manner. Then, an ELISA was used to evaluate the effect of the GS monomers on the secretion of $\operatorname{IgG}$ and $\operatorname{IgM}$ from B cells, revealing that GS monomers inhibited the secretion of $\operatorname{IgG}$ and $\operatorname{IgM}$ in a dose-dependent manner. The results indicated that GRg1, GRb1, GRh1 and GRg3 inhibited the growth of B cells and their products in a dose-dependent manner.

B-cell proliferation is regulated by complex molecular processes. To clarify how GS monomers exert their inhibitory effects, the mRNA expression of BLyS and BAFF, as well as their receptors were assessed by RT-qPCR. BlyS and BAFF are endogenous proteins that have an important role in the differentiation and maturation of B lymphocytes (17), and the present study demonstrated that the GS monomers decreased the LPS-stimulated expression of BlyS and BAFF, which means that GS monomers may affect the humoral immunity of SLE patients by reducing the expression of BAFF, BlyS and their receptors.

Apoptotic signaling is necessary for maintaining homeostasis and an adequate immune response. Fas/FasL and caspase- 3 are important cell apoptosis-associated proteins and therefore, the effects of GS on Fas/FasL and caspase-3 expression were assessed in the present study. It was revealed that GS promoted the expression of Fas/FasL and caspase-3 by LPS-induced CD19+ $\mathrm{B}$ cells.

The distribution of B-cell subsets is deregulated in the pathogenesis of SLE. The present study indicated that among the LPS-induced $\mathrm{CD} 19^{+} \mathrm{B}$ cells, the population of inactive B cells $\left(\mathrm{CD} 19^{+} \mathrm{CD} 27^{-}\right)$was reduced and that of memory B cells $\left(\mathrm{CD} 19^{+} \mathrm{CD} 27^{+}\right)$was increased. However, in the presence of GS monomers, the proportion of $\mathrm{CD} 19^{+} \mathrm{B}$ cells was decreased and the proportion of $\mathrm{CD} 27^{+} \mathrm{B}$ cells was increased, indicating that GS monomers inhibit the LPS-stimulated decrease in the proportion of inactive $\mathrm{B}$ cells and the increase in the proportion of memory B cells. Fc $\gamma$ RIIB (CD32) is an important inhibitory receptor on the B-cell surface that transmits inhibitory signals and reduces the immune response intensity when it binds with a ligand (23). The results of the present study indicated that GRb1, GRh1 and GRg3 reduced the LPS-stimulated inhibition of the expression of Fc $\gamma$ RIIB (CD32).

In summary, the present study comprehensively analyzed the effects of four GS monomers on humoral immunity in LPS-induced SLE and revealed their important role in the inhibition of humoral immunity in different pathways: GS monomers inhibit the proliferation of B cells and their secretions, induce apoptosis of $\mathrm{B}$ cells and regulate the proportion of B-cell subsets. These results suggest that the four GS monomers $\mathrm{Rb} 1, \mathrm{Rh} 1, \mathrm{Rg} 1$ and $\mathrm{Rg} 3$ may be potential candidates for the clinical treatment of SLE.

\section{Acknowledgements}

This study was supported by the National Natural Science Foundation of China (grant nos. 81173388 and 81673740) and the Three-Year Action Plan Project for Public Health in Shanghai (grant no. ZY3-CCCX-3-7002).

\section{References}

1. Tsokos GC: Systemic lupus erythematosus. N Engl J Med 365: 2010-2021, 2011.

2. Lisnevskaia L, Murphy G and Isenberg D: Systemic lupus erythematosus. Lancet 384: 1878-1888, 2014.

3. Goodnow CC, prent J, Fazekas de St Groth B and Vinuesa CG: Cellular and genetic mechanisms of self tolerance and autoimmunity. Nature 435: 590-597, 2005.

4. Hoffman RW: T cells in the pathogenesis of systemic lupus erythematosus. Clin Immunol 113: 4-13, 2004.

5. Dolff S, Quandt D, Wilde B, Feldkamp T, Hua F, Cai X, Specker C, Kribben A, Kallenberg CG and Witzke O: Increased expression of costimulatory markers CD134 and CD80 on interleukin-17 producing $\mathrm{T}$ cells in patients with systemic lupus erythematosus. Arthritis Res Ther 12: R150, 2010.

6. Lee EJ, Ko E, Lee J, Rho S, Ko S, Shin MK, Min BI, Hong MC, Kim SY and Bae H: Ginsenoside Rg1 enhances CD4(+) T-cell activities and modulates Th1/Th2 differentiation. Int Immunopharmacol 4: 235-244, 2004.

7. Zhou T, Zu G, Wang X, Zhang X, Li S, Liang Z and Zhao J: Immunomodulatory and neuroprotective effects of ginsenoside Rg1 in the MPTP(1-methyl-4-phenyl-1,2,3,6-tetrahydr opyridine)-induced mouse model of Parkinson's disease. Int Immunopharmacol 29: 334-343, 2015.

8. Lee JH and Han Y: Ginsenoside Rg1 helps mice resist to disseminated candidiasis by Th1 type differentiation of CD4+ T cell. Int Immunopharmacol 6: 1424-1430, 2006.

9. Lee SY, Jeong JJ, Eun SH and Kim DH: Anti-inflammatory effects of ginsenoside $\mathrm{Rg} 1$ and its metabolites ginsenoside Rh1 and 20(S)-protopanaxatriol in mice with TNBS-induced colitis. Eur J Pharmacol 762: 333-343, 2015.

10. Bae J, Koo J, Kim S, Park TY and Kim MY: Ginsenoside Rp1 exerts anti-inflammatory effects via activation of dendritic cells and regulatory T cells. J Ginseng Res 36 375-382, 2012.

11. Schmittgen TD and Livak KJ: Analyzing real-time PCR data by the comparative $\mathrm{C}(\mathrm{T})$ method. Nat Protoc 3: 1101-1108, 2008.

12. Parodis L, Arnaud L, Gerhardsson J, Zickert A, Sundelin B, Malmstrom V,Svenungsson E and Gunnasson I: Antiphospholipid Antibodies in Lupus Nephritis. PLoS One 11: e0158076, 2016.

13. Umiker BR, McDonald G, Larbi A, Medina CO, Hobeika E, Reth $\mathrm{M}$ and Imanishi-Kari T: Production of IgG autoantibody requires expression of activation-induced deaminase in early-developing B cells in a mouse model of SLE. Eur J Immunol 44: 3093-3108, 2014.

14. Ferreira R, Barreto M, Santos E, Pereira C, Martins B, Andreia R, Crespo F, Viana JF, Vasconcelos C, Ferreira C, et al: Heritable factors shape natural human IgM reactivity to Ro60/ SS-A and may predispose for SLE-associated IgG anti-Ro and anti-La autoantibody production. J Autoimmun 25: 155-163, 2005.

15. Kerekov NS, Mihaylova NM, Grozdev I, Todorov TA, Nikolova M, Baleva M, Nikolova M, Prechl J, Erdei A and Tchorbanov AI: Elimination of autoreactive B cells in humanized SCID mouse model of SLE. Eur J Immunol 41: 3301-3311, 2011.

16. Schneider P: The role of APRIL and BAFF in lymphocyte activation. Curr Opin Immunol 17: 282-289, 2005.

17. Mercado U and Diaz-Molina R: B lymphocyte stimulator (BLyS/BAFF) level in sera of patients with lupus. Rev Med Inst Mex Seguro Soc 54: 334-337, 2016. 
18. Salazar-Camarena DC, Ortiz-Lazareno PC, Cruz A Oregon-Romero E, Machado-Contreras JR, Munoz-Valle JF, Orozco-Lopez M, Marin-Rosales M and Palafox-Sanchez CA: Association of BAFF, APRIL serum levels, BAFF-R, TACI and BCMA expression on peripheral B-cell subsets with clinical manifestations in systemic lupus erythematosus. Lupus 25: 582-592, 2016.

19. Skare TL, Ferri K and Santos MA: Systemic lupus erythematosus activity and beta two microglobulin levels. Sao Paulo Med J 132: 239-242, 2014.

20. Wakabayashi K, Inokuma S, Matsubara E, Onishi K, Asashima H, Nakachi S and Hagiwara K: Serum $\beta 2$-microglobulin level is a useful indicator of disease activity and hemophagocytic syndrome complication in systemic lupus erythematosus and adult-onset Still's disease. Clin Rheumatol 32: 999-1005, 2013.

21. Menard LC, Habte S, Gonsiorek W, Lee D, Banas D, Holloway DA, Manjarrez-Orduno N, Cunningham M, Stetsko D, Casano F, et al: B cells from African American lupus patients exhibit an activated phenotype. JCI Insight 1: e87310, 2016.

22. Iwata $\mathrm{S}$ and Tanaka $\mathrm{Y}$ : B-cell subsets, signaling and their roles in secretion of autoantibodies. Lupus 25 850-856, 2016.

23. Niederer HA, Clatworthy MR, Willcocks LC and Smith KGC: Fcgamma RIIB, Fcgamma RIIIB, and systemic lupus erythematosus. Ann N Y Acad Sci 1183: 69-88, 2010.

24. Blanco P, Ueno H and Schmitt N: T follicular helper (Tfh) cells in lupus: Activation and involvement in SLE pathogenesis. Eur J Immunol 46: 281-290, 2016.
25. Bouts YM, Wolthuis DFGJ, Dirkx MFM, Pieterse E, Simons EMF, Boekel AM, Dieker JW and Vlag J: Apoptosis and NET formation in the pathogenesis of SLE. Autoimmunity 45: 597-601, 2012

26. Su X, Pei Z and Hu S: Ginsenoside Re as an adjuvant to enhance the immune response to the inactivated rabies virus vaccine in mice. Int Immunopharmacol 20: 283-289, 2014.

27. You YL, Feng YL, Cai Q, Guan JL, Zhang LL, Xu MJ, Xu X and Ling CQ: Efficacy of ginsenosides combined with prednisone in patients with systemic lupus erythematosus: A prospective, randomized, double-blind, placebo-controlled trial. Zhong Xi Yi Jie He Xue Bao 8: 762-766, 2010 (In Chinese).

28. Hao Y, Wang P, Wu J and Qiu QY: Effects of ginsenoside and berberine on secretion of immunosuppressive cytokines in lung carcinoma cell line PG. Zhong Xi Yi Jie He Xue Bao 6: 278-282, 2008 (In Chinese).

29. Lohr J, Knoechel B and Abbas AK: Regulatory T cells in the periphery. Immunol Rev 212: 149-162, 2006.

30. Cheema GS, Roschke V, Hilbert DM and Stohl W: Elevated serum B lymphocyte stimulator levels in patients with systemic immune-based rheumatic diseases. Arthritis Rheum 44: 1313-1319, 2001.

31. Fu L, Lin-Lee YC, Pham LV, Tamayo A, Yoshimura L and Ford RJ: Constitutive NF-kappaB and NFAT activation leads to stimulation of the BLyS survival pathway in aggressive B-cell lymphomas. Blood 107: 4540-4548, 2006.

32. Liu YJ: Dendritic cell subsets and lineages, and their functions in innate and adaptive immunity. Cell 106: 259-262, 2001. 